\title{
"Cholesterol Paradox" in Atrial Fibrillation
}

\author{
Shinya Suzuki, MD, $\mathrm{PhD}$
}

A

trial fibrillation (AF) is the most common arrhythmia in developed countries, and the incidence almost doubles for each decade of life, leading to $25 \%$ of the average life time risk. Several reports have noted that the AF population will greatly increase in the future because of the aging of society. ${ }^{1}$ As well as appropriate management of the arrhythmia, which is closely associated with an increase in cardiovascular mortality and morbidity, 2,3 primary AF prevention would be of great interest, but would in turn require appropriate identification of people at a high risk for AF.

\section{Article p 2767}

Multiple risk factors for AF have been identified, including hypertension, type 2 diabetes, cardiovascular diseases, obesity, metabolic syndrome and chronic kidney disease. ${ }^{4,5}$ In this respect, dyslipidemia, which similarly is an important cardiovascular risk factor, should increase the risk for AF. Actually, several previous studies have demonstrated a relationship between low levels of high-density lipoprotein cholesterol (HDL-C) and the incidence or prevalence of AF. ${ }^{5,6}$ However, it is rather confusing that controversial relationships with $\mathrm{AF}$ have been reported regarding other lipid profiles; several reports have demonstrated an inverse relationship between total cholesterol (TC) and $\mathrm{AF}^{7,8}$ a cross-sectional report showed no relationship between lipoprotein (a) and AF, ${ }^{9}$ and diverse results have been demonstrated regarding triglycerides. ${ }^{5,8}$ Although the results are rather confusing, it seems to be generally true that a reverse epidemiology (ie, the "cholesterol paradox") does exist between lipid profiles and AF, whereby low levels of HDL-C and low-density lipoprotein cholesterol (LDL-C) or TC are positively related to increasing AF together.

In this issue of the Journal, Watanabe et $\mathrm{al}^{10}$ demonstrate in a large cohort $(28,449)$ of Japanese subjects who underwent annual health examinations that (1) low HDL-C level was strongly associated with an increased risk of developing $\mathrm{AF}$, and (2) at the same time, the TC and LDL-C levels were inversely associated with $\mathrm{AF}$, confirming the cholesterol paradox in AF.

In discussing the mechanisms underlying the reverse epidemiology, it would be easy to understand that a low level of HDL-C is associated with increasing AF, because it is linked to various cardiovascular diseases and risk factors. On the other hand, given the close relationship between a low level of HDL-C and high levels of LDL-C or TC, it is rather difficult to understand how low levels of LDL-C or TC are related to increased risk of AF. However, there are several possible mechanisms for the inverse relationship between LDL-C or $\mathrm{TC}$ and $\mathrm{AF}$.

First, although the TC level increases according to age in relatively younger populations, it decreases in individuals over 60-70 years old. ${ }^{11}$ Also, male sex is associated with a lower TC level. ${ }^{11}$ These relationships might explain the reverse association between TC and increasing AF, because increasing age and male sex strongly affect AF. However, this association seems to be unable to fully explain the inverse relationship, because in the analysis by Watanabe et $\mathrm{al}^{10}$ the effect of LDL-C on AF was still independent after adjustment by cofactors including age and sex.

Second, thyroid dysfunction might explain the inverse relationship. Although thyroid hormones stimulate the synthesis of cholesterol inducing the 3-hydroxy-3-methylglutarylcoenzyme A (HMG-CoA) reductase, they also upregulate the catabolism of cholesterol in the liver, activating the LDL receptors, leading consequently to reducing the LDL-C level. Therefore, there is an inverse relationship between an increasing level of thyroid hormone and the LDL-C or TC level. ${ }^{12}$ Thus, given the relationship between hyperthyroidism (both clinical and subclinical) and AF development, it is conceivable that low cholesterol is associated with increasing AF. However, to date, the role of thyroid hormone was not significant in a small cohort, ${ }^{8}$ and unfortunately Watanabe et al do not provide data regarding thyroid function. ${ }^{10}$

Third, inflammation might explain the inverse relationship. Although we usually believe that the level of LDL-C or TC is positively associated with systemic inflammation (eg, highsensitivity C-reactive protein (CRP) or interleukin 6), it was not necessarily so in several reports to date..$^{13,14}$ Rather, one report demonstrated that the LDL-C level was inversely related to CRP level in women. ${ }^{13}$ As previously reported, increasing inflammation predicts the future development of AF. Therefore, it would be likely that there remains the possibility that a low level of LDL-C or low TC is linked to increasing AF via the pathogenesis of enhanced inflammation.

Interestingly, Watanabe et $\mathrm{al}^{10}$ mention sex differences in the relationship between lipid profiles and $\mathrm{AF}$, referring to the difference in the electrophysiological properties of the atrium and also in hormonal characteristics, including menopause. Thus, the interrelationship between lipid profiles and AF has a very complicated pathogenesis in the background, which supposedly leads to the controversial results in the previous small or cross-sectional analyses. ${ }^{7-9}$

In conclusion, it is noteworthy that the cholesterol paradox in

The opinions expressed in this article are not necessarily those of the editors or of the Japanese Circulation Society.

Received October 4, 2011; accepted October 5, 2011; released online October 26, 2011

Department of Cardiovascular Medicine, The Cardiovascular Institute, Tokyo, Japan

Mailing address: Shinya Suzuki, MD, PhD, Department of Cardiovascular Medicine, The Cardiovascular Institute, 3-2-19 Nishiazabu,

Minato-ku, Tokyo 106-0031, Japan. E-mail: sinsuz-tky@umin.ac.jp

ISSN-1346-9843 doi:10.1253/circj.CJ-11-1134

All rights are reserved to the Japanese Circulation Society. For permissions, please e-mail: cj@j-circ.or.jp 
AF was ascertained in the analysis of a large, prospective cohort by Watanabe et al. ${ }^{10}$ However, it is still unclear what the cholesterol paradox in AF truly means, because until now the effects of inflammation, thyroid function or sex hormones on the reverse epidemiology have not fully examined. Therefore, further investigation with precise data is necessary to understand the complex mechanisms of the cholesterol paradox in AF.

\section{Disclosures}

None declared

\section{References}

1. Inoue H, Fujiki A, Origasa H, Ogawa S, Okumura K, Kubota I, et al. Prevalence of atrial fibrillation in the general population of Japan: An analysis based on periodic health examination. Int J Cardiol 2009; 137: $102-107$

2. Goto S, Ikeda Y, Shimada K, Uchiyama S, Origasa H, Kobayashi H; The J-TRACE Investigators. One-year cardiovascular event rates in Japanese outpatients with myocardial infarction, stroke, and atrial fibrillation: Results from the Japan Thrombosis Registry for Atrial Fibrillation, Coronary, or Cerebrovascular Events (J-TRACE). Circ J 2011; 75: 2598-2604.

3. Adachi H. Attributable risks of atrial fibrillation in Japan from the view point of epidemiology. Circ J 2011; 75: 2537-2538.

4. Miyasaka Y, Barnes ME, Bailey KR, Cha SS, Gersh BJ, Seward JB, et al. Mortality trends in patients diagnosed with first atrial fibrillation: A 21-year community-based study. J Am Coll Cardiol 2007; 49: $986-992$.

5. Watanabe H, Tanabe N, Watanabe T, Darbar D, Roden DM, Sasaki $\mathrm{S}$, et al. Metabolic syndrome and risk of development of atrial fibril- lation: The Niigata Preventive Medicine Study. Circulation 2008; 117: $1255-1260$.

6. Haywood LJ, Ford CE, Crow RS, Davis BR, Massie BM, Einhorn $\mathrm{PT}$, et al. Atrial fibrillation at baseline and during follow-up in ALLHAT (Antihypertensive and Lipid-Lowering Treatment to Prevent Heart Attack Trial). J Am Coll Cardiol 2009; 54: 2023-2031.

7. Psaty BM, Manolio TA, Kuller LH, Kronmal RA, Cushman M, Fried $\mathrm{LP}$, et al. Incidence of and risk factors for atrial fibrillation in older adults. Circulation 1997; 96: 2455-2461.

8. Annoura M, Ogawa M, Kumagai K, Zhang B, Saku K, Arakawa K. Cholesterol paradox in patients with paroxysmal atrial fibrillation. Cardiology 1999; 92: 21-27.

9. Díaz-Peromingo JA, Albán-Salgado A, García-Suárez F, Sánchez-Leira J, Saborido-Froján J, Iglesias-Gallego M. Lipoprotein(a) and lipid profile in patients with atrial fibrillation. Med Sci Monit 2006; 12: CR122-CR125.

10. Watanabe H, Tanabe N, Yagihara N, Watanabe T, Aizawa Y, Kodama M. Association between lipid profile and risk of atrial fibrillation: Niigata Preventive Medicine Study. Circ J 2011; 75: 2767 2774.

11. Ministry of Health, Labor and Welfare (MHLW) Statistical Database: http://wwwhakusyo.mhlw.go.jp/wp/index.htm (in Japanese) (accessed 4 October, 2011).

12. Asvold BO, Vatten LJ, Nilsen TI, Bjøro T. The association between TSH within the reference range and serum lipid concentrations in a population-based study: The HUNT Study. Eur J Endocrinol 2007; 156: $181-186$.

13. Folsom AR, Pankow JS, Tracy RP, Arnett DK, Peacock JM, Hong $\mathrm{Y}$, et al. Association of C-reactive protein with markers of prevalent atherosclerotic disease. Am J Cardiol 2001; 88: 112-117.

14. Saito M, Ishimitsu T, Minami J, Ono H, Ohrui M, Matsuoka H. Relations of plasma high-sensitivity C-reactive protein to traditional cardiovascular risk factors. Atherosclerosis 2003; 167: 73-79. 